\title{
Gene expression networks in COPD: microRNA and mRNA regulation
}

\author{
Michael E Ezzie, ${ }^{1}$ Melissa Crawford, ${ }^{1}$ Ji-Hoon Cho, ${ }^{2}$ Robert Orellana, ${ }^{1}$ Shile Zhang, ${ }^{2}$ \\ Richard Gelinas, ${ }^{2}$ Kara Batte, ${ }^{1}$ Lianbo Yu, ${ }^{1}$ Gerard Nuovo, ${ }^{1}$ David Galas, ${ }^{2}$ Philip Diaz, ${ }^{1}$ \\ Kai Wang, ${ }^{2}$ S Patrick Nana-Sinkam ${ }^{1}$
}

\begin{abstract}
- Additional data are published online only. To view these files please visit the journal online (http://thorax.bmj.com/content/ 67/2.toc).

1 Department of Medicine, Dorothy M. Davis Heart and Lung Research Institute, The Ohio State University Medical Center, Columbus, Ohio, USA ${ }^{2}$ Institute for Systems Biology, Seattle, Washington, USA
\end{abstract}

\section{Correspondence to}

Dr S Patrick Nana-Sinkam, Ohio State University Medical Center, Davis HLRI, 473 W 12th Ave,

Room 201, Columbus, $\mathrm{OH}$ 43210, USA; patrick.

nana-sinkam@osumc.edu

$\mathrm{ME}$ and $\mathrm{MC}$ contributed equally to this manuscript.

Received 24 February 2011 Accepted 21 August 2011 Published Online First 22 September 2011

\section{ABSTRACT}

Background The mechanisms underlying chronic obstructive pulmonary disease (COPD) remain unclear. MicroRNAs (miRNAs or miRs) are small non-coding RNA molecules that modulate the levels of specific genes and proteins. Identifying expression patterns of miRNAs in COPD may enhance our understanding of the mechanisms of disease. A study was undertaken to determine if miRNAs are differentially expressed in the lungs of smokers with and without COPD. miRNA and mRNA expression were compared to enrich for biological networks relevant to the pathogenesis of COPD.

Methods Lung tissue from smokers with no evidence of obstructive lung disease $(n=9)$ and smokers with COPD $(n=26)$ was examined for miRNA and mRNA expression followed by validation. We then examined both miRNA and mRNA expression to enrich for relevant biological pathways.

Results 70 miRNAs and 2667 mRNAs were differentially expressed between lung tissue from subjects with COPD and smokers without COPD. miRNA and mRNA expression profiles enriched for biological pathways that may be relevant to the pathogenesis of COPD including the transforming growth factor $\beta$, Wnt and focal adhesion pathways. miR-223 and miR-1274a were the most affected miRNAs in subjects with COPD compared with smokers without obstruction. miR-15b was increased in COPD samples compared with smokers without obstruction and localised to both areas of emphysema and fibrosis. miR-15b was differentially expressed within GOLD classes of COPD. Expression of SMAD7, which was validated as a target for miR-15b, was decreased in bronchial epithelial cells in COPD. Conclusions miRNA and mRNA are differentially expressed in individuals with COPD compared with smokers without obstruction. Investigating these relationships may further our understanding of the mechanisms of disease.

\section{INTRODUCTION}

Chronic obstructive pulmonary disease (COPD) is a worldwide epidemic primarily attributable to the effects of cigarette smoke. It is a heterogeneous disease defined by airflow limitation that is not fully reversible and an abnormal inflammatory response of the lung to noxious stimuli. ${ }^{1}$ Mechanisms implicated include those directly attributable to the effects of cigarette smoke such as cellular injury, inflammation and abnormal repair. ${ }^{2}$

\section{Key messages}

What is the key question?

- Chronic obstructive pulmonary disease (COPD) is a worldwide health crisis mostly attributable to cigarette smoking.

- The precise mechanisms underlying COPD development are not clear, but genomic and proteomic studies are improving our understanding of the pathogenesis of this disease.

- Researchers have identified abnormal expression of microRNAs (miRNAs or miRs) in several types of cancers, but our knowledge of the significance of these small molecules in diseases other than cancer including COPD is just emerging.

What is the bottom line and why read on?

- 70 miRNAs that were differentially expressed in lung tissue from smokers without COPD and those with COPD (GOLD stages 1, 2 and 4) were identified.

- The correlation between differentially expressed miRNAs and genes suggests potentially functionally relationships that may contribute to the pathogenesis of COPD.

MicroRNAs (miRNAs, miR) are one member of a family of small non-coding RNAs (approximately 21-25 nucleotides long) encoded in the genome of organisms ranging from animals and plants to viruses. ${ }^{3}$ These molecules represent components of the human genome that were previously thought to be non-functional. miRNAs are integral to key biological functions and modulate both gene and protein levels by either destabilising transcripts or inhibiting protein translation. Given the relative redundancy of complementary sequences between miRNAs and their target mRNA, single miRNAs have the capacity to regulate tens to hundreds of genes simultaneously. In fact, it is estimated that miRNAs may target up to one-third of the transcriptome. ${ }^{4}$

miRNA deregulation has been implicated in the pathogenesis of several diseases including both haematological and solid malignancies. miRNA expression patterns in primary tumour tissues, blood, sputum and urine are being investigated as biomarkers for both diagnosis and prognosis in disease. These miRNA signatures may eventually be applied to clinical practice. Our knowledge of the role of miRNAs in the pathogenesis of lung 
Table 1 Demographic characteristics of study patients

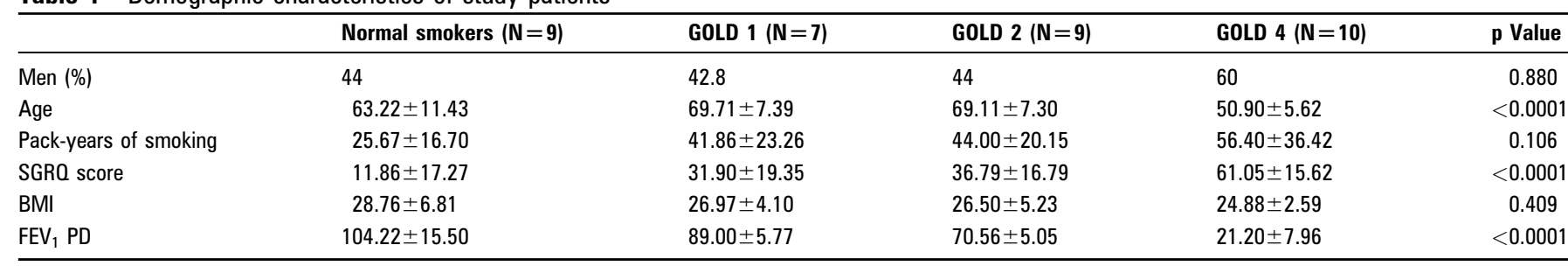

$\mathrm{BMI}$, body mass index; FEV 1 PD, forced expiratory volume in $1 \mathrm{~s}$ percentage predicted; NA, not available; SGRQ, St George Respiratory Questionnaire score.

disease is rapidly expanding, and miRNAs appear to be important in maintaining homeostasis during lung development and may have a pathogenic role in lung disease. ${ }^{6}$ In addition, miRNAs may be involved in the regulation of inflammation in the lung in response to exogenous stimuli in animal models. ${ }^{7} 8$

Little is known regarding the role of miRNAs in COPD. Two studies have investigated the effects of cigarette smoke on miRNA expression. ${ }^{9} 10$ In the first study 24 miRNAs were significantly downregulated between smoke-exposed rats and sham groups. ${ }^{9}$ In the second study the effects of smoke exposure on miRNA expression in mice were investigated. ${ }^{10}$ The majority of deregulated miRNAs in this study were also downregulated.

Similar studies are being conducted in specific cell types in smokers and subjects with COPD. Schembri et al compared miRNA and mRNA expression in airway epithelial cells from smokers versus never smokers. ${ }^{11}$ Twenty-eight miRNAs were differentially expressed, with the majority downregulated in smokers. Sato et al examined the expression of $m i R-146 a$ in fibroblasts from subjects with and without COPD. ${ }^{12}$ miR-146a expression in cultured fibroblasts was reported to correlate with COPD severity as assessed by expiratory airflow.

Our goal in this study was to determine if miRNAs were differentially expressed in the lungs of patients with COPD and if miRNA expression may be linked to mRNA expression and thus biological pathways relevant to the pathogenesis of COPD. We compared miRNA and mRNA expression patterns in lung tissue from subjects with different Global Initiative for Obstructive Lung Disease (GOLD) stages of COPD and smokers without airflow limitation. We enriched for predicted miRNA targets in our group of deregulated mRNAs. Lastly, we identified transforming growth factor (TGF)- $\beta$, Wnt and focal adhesion pathways as potential pathways in which miRNAs may be relevant to the pathogenesis of COPD.

\section{METHODS}

Additional details of methods are shown in the online supplement.

\section{Subject selection}

Thirty-five tissue samples were procured through a Lung Tissue Research Consortium approved project (\#07-99-0008) for the purposes of miRNA and mRNA analysis. Clinical information available for the subjects included age, gender, height, weight and smoking history. Test results including spirometry, pathological diagnosis and the results of the St George Respiratory Questionnaire health surveys were available.

\section{Tissue processing and RNA isolation}

Total RNA was isolated from frozen tissue samples using a freeze fracture protocol, followed by Trizol extraction and precipitation at $-20^{\circ} \mathrm{C}$ overnight to increase the yield of small RNAs. RNA integrity was determined by capillary electrophoresis on an Agilent 2100 Bioanalyzer. Only RNA with an integrity number $\geq 7$ was used in the profiling studies.

\section{miRNA microarray}

miRNAs were profiled in subjects with COPD $(\mathrm{N}=19)$ and normal smokers $(\mathrm{N}=8)$ using Exiqon miRNA microarrays according to the manufacturer's instructions (Exiqon, Woburn, Massachusetts, USA). The labelled miRNA probes were hybridised to the miRCURY LNA arrays v. 11.0 for $16 \mathrm{~h}$ at $56^{\circ} \mathrm{C}$. After hybridisation the arrays were washed and scanned at $5 \mu \mathrm{m}$ resolution using a ScanArray Express (Perkin Elmer, Waltham, Massachusetts, USA).

\section{Messenger RNA microarray}

Samples were prepared for mRNA microarray analysis using Agilent Quick Amp Labeling technologies (Santa Clara, California, USA). Hybridised slides were then washed and scanned with ScanArray Express (Perkin Elmer).

\section{mRNA and miRNA microarray data processing}

For mRNA data, raw intensities from all samples were merged, normalised using the quantile method and transformed into $\log _{2}$ scale. ${ }^{13}$ Present probes with mean intensity over all samples larger than the global mean intensity were chosen and used for

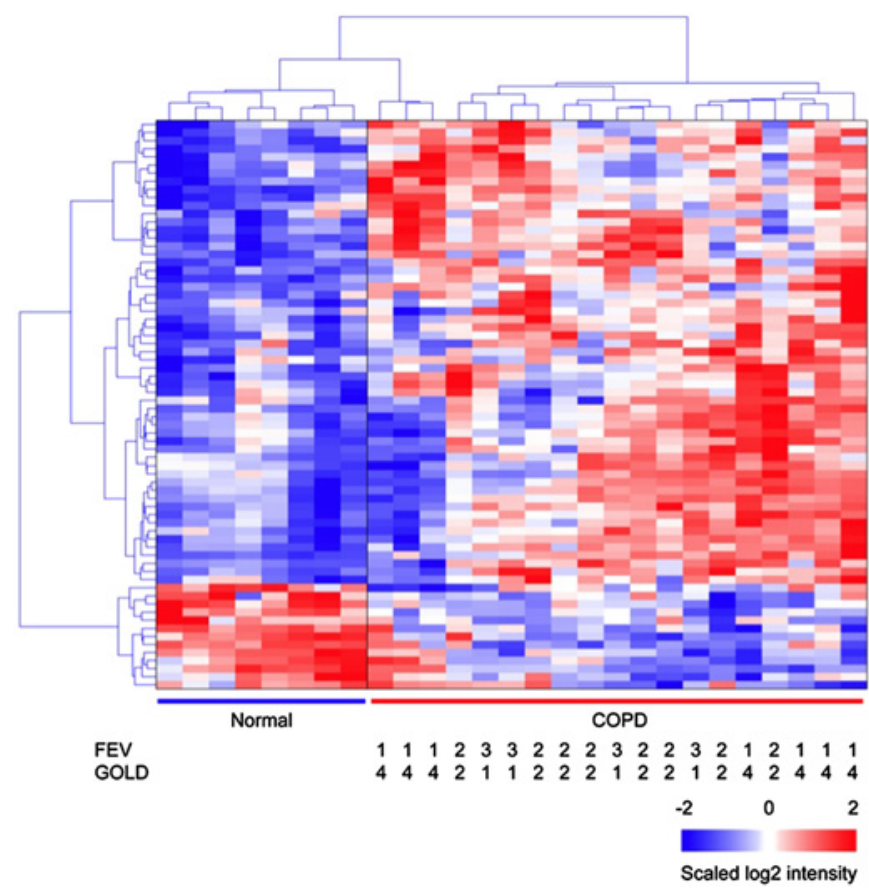

Figure 1 Hierarchical clustering result of differentially expressed microRNAs (miRNAs) in lungs from subjects with chronic obstructive pulmonary disease (COPD) compared to smokers without COPD. Exiqon miRCURY LNA microRNA Array v11 was used for miRNA expression profiling. Seventy differentially expressed miRNAs (DEmiRNAs) were identified between COPD samples $(n=19)$ and smokers without obstruction $(n=8)$ which showed a positive false discovery rate $<0.05$ and fold changes $> \pm 1.5$ using the LIMMA method. 
Table 2 Top 10 upregulated microRNAs in lungs from subjects with COPD compared with smokers without COPD

\begin{tabular}{llll}
\hline & $\begin{array}{l}\text { Fold difference } \\
\text { (COPD/normal smokers) }\end{array}$ & p Value & pFDR value \\
\hline hsa-miR-223 & 2.93 & $6.63 \mathrm{E}-04$ & $1.37 \mathrm{E}-03$ \\
hsa-miR-1274a & 2.73 & $3.19 \mathrm{E}-10$ & $4.44 \mathrm{E}-09$ \\
hsa-miR-144 & 2.38 & $2.83 \mathrm{E}-03$ & $4.26 \mathrm{E}-03$ \\
hsa-miR-374a & 2.25 & $1.72 \mathrm{E}-04$ & $4.74 \mathrm{E}-04$ \\
hsa-miR-664 & 2.21 & $2.00 \mathrm{E}-08$ & $2.02 \mathrm{E}-07$ \\
hsa-miR-148a & 2.15 & $2.34 \mathrm{E}-07$ & $1.68 \mathrm{E}-06$ \\
hsa-miR-766 & 2.06 & $1.05 \mathrm{E}-05$ & $4.76 \mathrm{E}-05$ \\
hsa-miR-486-5p & 2.05 & $3.26 \mathrm{E}-04$ & $8.21 \mathrm{E}-04$ \\
hsa-miR-10a & 2.05 & $7.47 \mathrm{E}-04$ & $1.46 \mathrm{E}-03$ \\
hsa-miR-451 & 2.00 & $5.39 \mathrm{E}-02$ & $4.59 \mathrm{E}-02$ \\
\hline
\end{tabular}

COPD, chronic obstructive pulmonary disease; pFDR, positive false discovery rate.

further statistical analysis. LIMMA ${ }^{14}$ and OVALUE $^{15} \mathrm{R}$ packages were used to perform statistical testing of differential mRNA and miRNA expression between control smoker and COPD samples and to compute the positive false discovery rate (pFDR), respectively. Present probes were used for statistical testing to increase the ratio of true positives to false positives, ${ }^{16}$ and differentially expressed mRNAs and miRNAs were defined as having a $\mathrm{pFDR}<0.05$ with at least \pm 1.5 -fold change between the groups.

\section{Quantitative reverse transcription PCR validation}

Independent assays were performed using quantitative reverse transcription PCR (qRT-PCR) on all patient samples for individual miRNA (miR-15b, miR-223, miR-1274a and miR-424) and mRNA (telomerase associated protein 1 (TEP1), interleukin 6 (IL6), catalase (CAT) and mothers against decapentaplegic homologue 7 (Drosophila) (SMAD7) (Applied Biosystems, Foster City, California, USA). All RT-PCR experiments were performed in three independent experiments conducted in triplicate on all study samples. Data were presented relative to either 18s for mRNA or U43 for miRNA based on calculations of $2^{(-\Delta C t)}$. Statistical significance was defined as $p<0.05$ as measured by the

Table 3 Top 10 downregulated microRNAs in lungs from subjects with COPD compared with smokers without COPD

\begin{tabular}{llll}
\hline miRNA & $\begin{array}{l}\text { Fold difference } \\
\text { (COPD/normal smokers) }\end{array}$ & p Value & pFDR value \\
\hline hsa-miR-923 & -5.06 & $5.88 \mathrm{E}-06$ & $2.91 \mathrm{E}-05$ \\
hsa-miR-937 & -2.36 & $1.89 \mathrm{E}-06$ & $1.08 \mathrm{E}-05$ \\
hsa-miR-422a & -2.12 & $1.45 \mathrm{E}-06$ & $8.74 \mathrm{E}-06$ \\
hsa-miR-576-3p & -2.06 & $1.57 \mathrm{E}-06$ & $9.22 \mathrm{E}-06$ \\
hsa-miR-513a-5p & -2.06 & $3.57 \mathrm{E}-04$ & $8.54 \mathrm{E}-04$ \\
hsa-miR-25* & -2.01 & $2.10 \mathrm{E}-07$ & $1.56 \mathrm{E}-06$ \\
hsa-miR-99b* & -1.81 & $1.23 \mathrm{E}-05$ & $5.25 \mathrm{E}-05$ \\
hsa-miR-125b-1* & -1.75 & $1.38 \mathrm{E}-05$ & $5.70 \mathrm{E}-05$ \\
hsa-miR-24 & -1.75 & $1.59 \mathrm{E}-04$ & $4.49 \mathrm{E}-04$ \\
hsa-miR-187* & -1.64 & $3.14 \mathrm{E}-04$ & $8.04 \mathrm{E}-04$ \\
\hline
\end{tabular}

*indicates miRNA on the opposite arm of the hairpin during processing. COPD, chronic obstructive pulmonary disease; pFDR, positive false discovery rate.

Student $t$ test or ANOVA (see tables E1 and E2 in online supplement for sequences of miRNA and mRNA probes).

\section{Functional enrichment study}

In order to identify Kyoto Encyclopedia of Genes and Genomes $(\mathrm{KEGG})^{17}$ pathways associated with a set of genes, we used DAVID $^{18}$ and obtained the list of enriched pathways. Their $p$ values were computed by a modified Fisher exact test called the EASE score method. ${ }^{18}$

\section{Target prediction and network analysis}

Predicted target genes for miRNAs were obtained using TargetScan v5.1, PicTar and miRanda. For differentially expressed miRNAs, all predicted targets in human genes and predicted targets overlapping with differentially expressed genes were used to perform KEGG pathway enrichment analysis. To describe the potential relationship between differentially expressed genes and miRNAs in a KEGG pathway, the predicted miRNA gene pairs from TargetScan showing negative expression correlations $(<-0.5)$ were incorporated into the pathway diagram. A modified KEGG pathway diagram was generated using Cytoscape. ${ }^{19}$

Figure 2 Quantitative reverse transcription polymerase chain reaction (qRT-PCR) validation of differentially expressed microRNAs (miRNAs). qRTPCR was performed on the same RNA samples (nine normal smokers and 26 subjects with chronic obstructive pulmonary disease) by individual miRNA for (A) miR-15b, (B) miR-223, (C) miR-1274a and (D) miR-424. All RTPCR experiments were performed in two independent experiments conducted in triplicate. Data are presented as $2^{(-\Delta \mathrm{Ct})}$ relative to U43. There was a statistically significant difference as measured by the Student $t$ test in subjects with chronic obstructive pulmonary disease (COPD) compared with normal smokers for miR-15b, miR223, miR-1274a and miR-424.
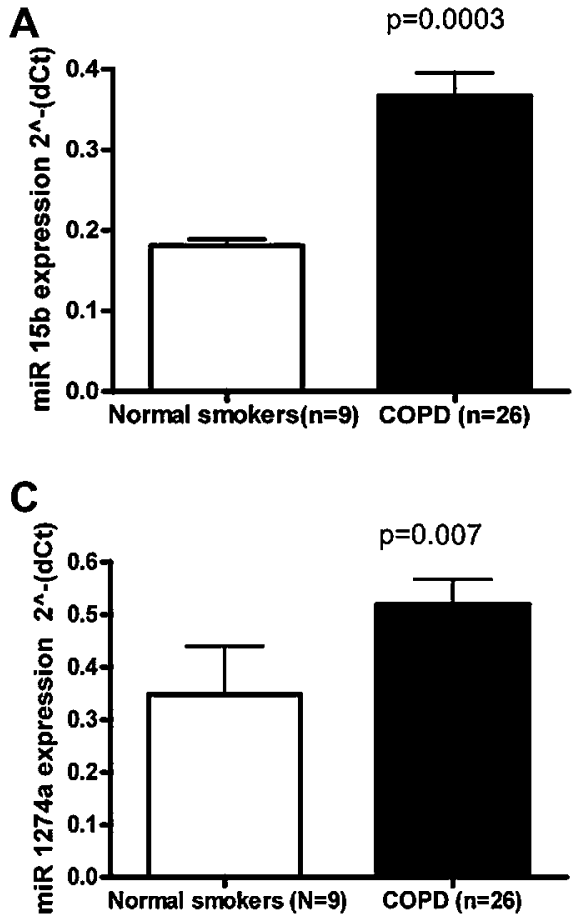

B

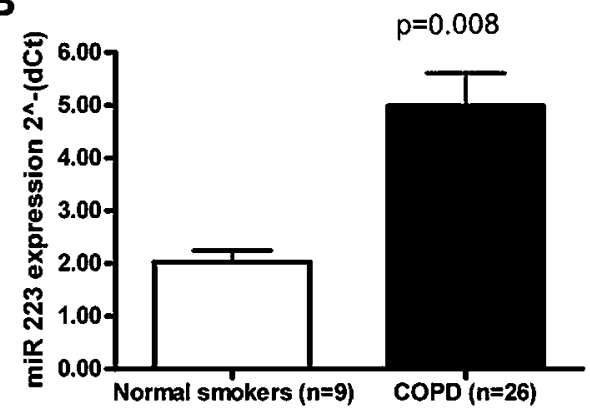

D

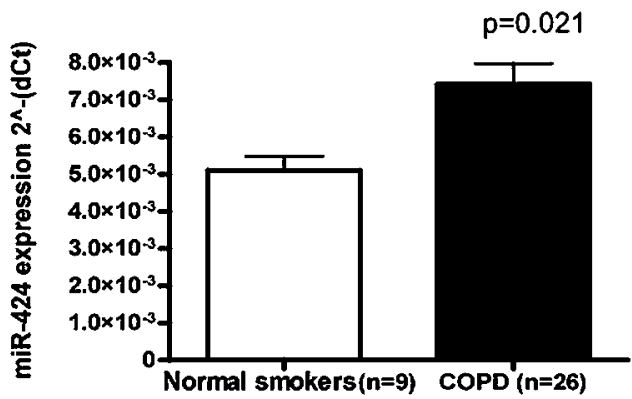




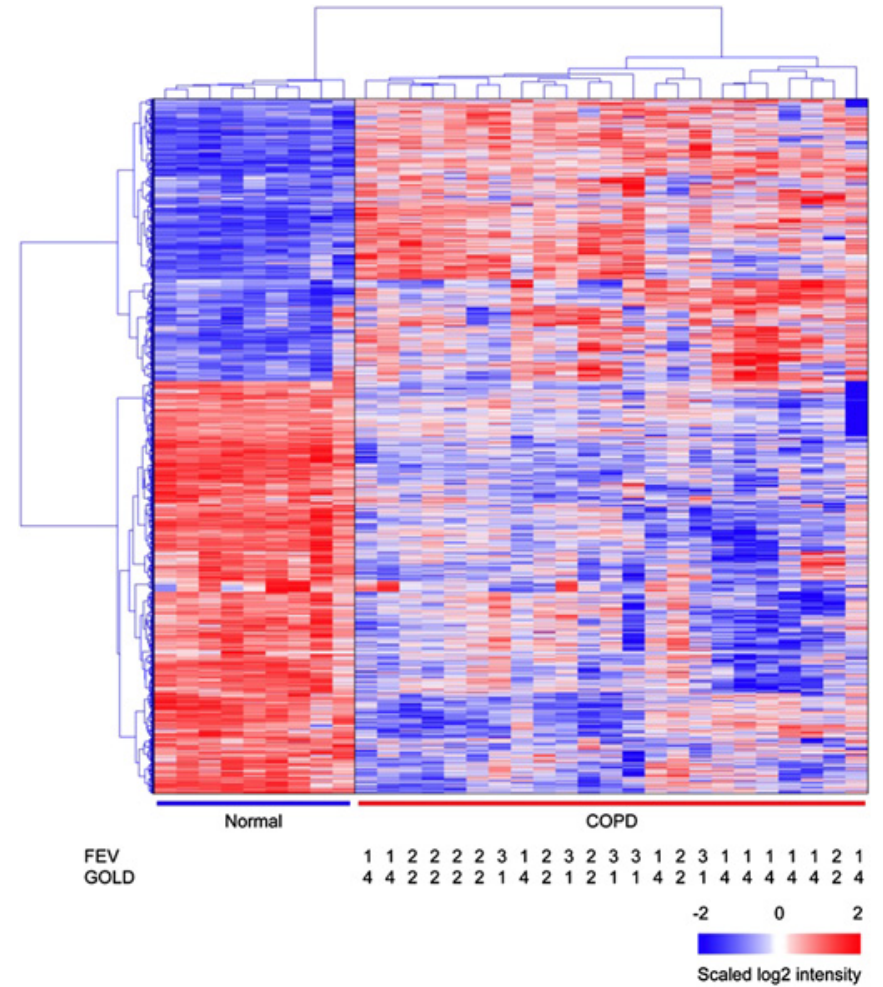

Figure 3 Hierarchical clustering result of differentially expressed genes in subjects with chronic obstructive pulmonary disease (COPD) compared with smokers without COPD. There were 2667 differentially expressed genes between subjects with COPD $(N=23)$ and smokers without COPD $(\mathrm{N}=9)$. Hierarchical clustering result showed the clear separation of COPD patient samples from smokers without COPD samples. Normal: smokers without airflow limitation.

\section{In situ hybridisation and co-localisation}

Co-localisation analyses of SMAD7, cytokeratin AE $1 / 3$ and miR-15b expression were conducted as previously described. ${ }^{20}$ After development the slide was analysed with the Nuance system (Cambridge Research and Instrumentation, Hopkinton, $\mathrm{MA}$ ). The Nuance system converts the blue and brown signals to fluorescent blue and red, respectively, then mixes them to determine if a given cell contains both targets. The negative controls were the omission of the probe and the use of a scrambled probe, as previously described. ${ }^{20}$

\section{Transfection studies and western blot analyses}

Details of transfection studies and western blot analyses are shown in the online supplement.

\section{TGF $\beta$ treatment}

Beas2B cells were transfected with either scrambled or premiR15b as described above. $72 \mathrm{~h}$ after transfection the cells were starved for $6 \mathrm{~h}$ followed by treatment with TGF $\beta(5 \mathrm{ng} / \mathrm{ml}$; Sigma, St Louis, Missouri, USA). The cells were harvested at 10, 15 and 30 min and assessed for phosphorylated SMAD 3 protein expression (Cell Signaling, Danvers, Massachusetts, USA).

\section{Migration assay}

The migration rate was assayed using the IBIDI culture insert (München, Germany). Images were taken on an Olympus IX81 immediately (time 0) and again at 8 and $24 \mathrm{~h}$. Seven random widths were measured across the wound at time 0 . The number of pixels was converted to microns and the line was then superimposed onto the subsequent time points. The mean and $\mathrm{SD}$ of the seven lines was calculated using ImageJ software to determine the distance of wound closure. Experiments were performed in triplicate.

\section{RESULTS}

\section{Study subjects}

Tissue samples were obtained from subjects with GOLD stages 1 , 2 and 4 COPD $(\mathrm{N}=26)$ and from smokers without evidence of obstruction $(\mathrm{N}=9)$ from the Lung Tissue Research Consortium. There were no pathological or clinical diagnoses of cancer across the COPD or control tissue specimens. GOLD stage 4 tissue was obtained from explanted lungs. Tissue from smokers without airflow obstruction and GOLD stages 1 and 2 tissue was obtained mainly by wedge resection with pathology showing no evidence of cancer. Demographic information is presented in table 1 with accompanying summary statistics for each group.

There was an overall difference between the mean ages of all subjects $(p<0.0001)$. Subjects with GOLD stage 4 COPD were younger than those with GOLD 1 COPD $(p<0.001)$, GOLD 2 COPD $(p<0.001)$ and smokers without airflow limitation

Table 4 Top 10 upregulated mRNA in lung tissue from subjects with COPD compared with smokers without COPD

\begin{tabular}{|c|c|c|c|c|c|c|}
\hline Gene ID & Gene title & Gene symbol & $\begin{array}{l}\text { Fold difference } \\
\text { (COPD/normal smokers) }\end{array}$ & p Value & pFDR value & Function \\
\hline 9507 & $\begin{array}{l}\text { ADAM metallopeptidase with } \\
\text { thrombospondin type } 1 \text { motif, } 4\end{array}$ & ADAMTS4 & 8.91 & $2.16 \mathrm{E}-04$ & $4.02 \mathrm{E}-04$ & Proteolytic activity \\
\hline 7011 & Telomerase-associated protein 1 & TEP1 & 7.24 & $4.88 \mathrm{E}-13$ & $5.06 \mathrm{E}-11$ & $\begin{array}{l}\text { Alternative splicing, } \\
\text { nucleo-cytoplasmic transport }\end{array}$ \\
\hline 10949 & $\begin{array}{l}\text { Heterogeneous nuclear ribonucleoprotein } \\
\text { AO }\end{array}$ & HNRNPAO & 6.86 & $8.02 \mathrm{E}-22$ & $5.24 \mathrm{E}-18$ & $\begin{array}{l}\text { mRNA processing, transport } \\
\text { and metabolism }\end{array}$ \\
\hline 2304 & $\begin{array}{l}\text { Forkhead box E1 (thyroid transcription } \\
\text { factor 2) }\end{array}$ & F0XE1 & 6.30 & $4.02 \mathrm{E}-05$ & $1.01 \mathrm{E}-04$ & $\begin{array}{l}\text { Transcription factor, thyroid } \\
\text { gland organogenesis }\end{array}$ \\
\hline 4001 & Lamin B1 & LMNB1 & 6.05 & $8.44 \mathrm{E}-12$ & 4.52E-10 & $\begin{array}{l}\text { Nuclear stability, chromatin } \\
\text { structure }\end{array}$ \\
\hline 117245 & HRAS-like suppressor family, member 5 & HRASLS5 & 5.26 & $1.59 \mathrm{E}-17$ & $1.44 \mathrm{E}-14$ & Transferase, catalytic activity \\
\hline 3569 & Interleukin 6 (interferon, beta 2) & IL6 & 5.18 & $1.50 \mathrm{E}-03$ & 2.01E-03 & Inflammation, B cell differentiation \\
\hline 6280 & S100 calcium binding protein A9 & S100A9 & 5.14 & $8.17 \mathrm{E}-07$ & $4.14 \mathrm{E}-06$ & $\begin{array}{l}\text { Cell cycle progression, differentiation, } \\
\text { immune system }\end{array}$ \\
\hline 6696 & $\begin{array}{l}\text { Secreted phosphoprotein } 1 \text { (osteopontin, bone } \\
\text { sialoprotein I, early T lymphocyte activation 1) }\end{array}$ & SPP1 & 5.10 & $6.58 \mathrm{E}-05$ & $1.51 \mathrm{E}-04$ & $\begin{array}{l}\text { Metabolic process, cellular } \\
\text { organisation, binding }\end{array}$ \\
\hline 27097 & $\begin{array}{l}\text { TAF5-like RNA polymerase II, p300/CBP-associated } \\
\text { factor (PCAF)-associated factor, } 65 \mathrm{kDa}\end{array}$ & TAF5L & 4.95 & $2.05 \mathrm{E}-12$ & $1.51 \mathrm{E}-10$ & Histone acetylase \\
\hline
\end{tabular}


Table 5 Top 10 downregulated mRNA in lung tissue from subjects with COPD compared with smokers without COPD

\begin{tabular}{|c|c|c|c|c|c|c|}
\hline Gene ID & Gene title & Gene symbol & $\begin{array}{l}\text { Fold difference } \\
\text { (COPD/normal smokers) }\end{array}$ & p Value & pFDR value & Function \\
\hline 22870 & SAPS domain family, member 1 & SAPS1 & -4.46 & $3.15 \mathrm{E}-03$ & 3.69E-03 & Protein phosphatase \\
\hline 6435 & $\begin{array}{l}\text { Surfactant, pulmonary-associated protein } \\
\text { A1B }\end{array}$ & SFTPA1B & -4.23 & $2.90 \mathrm{E}-08$ & $2.76 \mathrm{E}-07$ & Binds surfactant phospholipids \\
\hline 5507 & $\begin{array}{l}\text { Protein phosphatase 1, regulatory } \\
\text { (inhibitor) subunit } 3 \mathrm{C}\end{array}$ & PPP1R3C & -4.17 & $3.99 \mathrm{E}-05$ & $1.01 \mathrm{E}-04$ & $\begin{array}{l}\text { Glycogen-targeting subunit, increases } \\
\text { glycogen }\end{array}$ \\
\hline 2662 & Growth differentiation factor 10 & GDF10 & -4.14 & 3.07E-05 & 8.04E-05 & TGF $\beta$ signalling \\
\hline 5350 & Phospholamban & PLN & -3.93 & $1.78 \mathrm{E}-06$ & $7.72 \mathrm{E}-06$ & Calcium regulation \\
\hline 25928 & Sclerostin domain containing 1 & SOSTDC1 & -3.87 & $2.68 \mathrm{E}-04$ & 4.79E-04 & $\begin{array}{l}\text { Inhibits TGF } \beta \text { signaling and enhances } \\
\text { Wnt signalling }\end{array}$ \\
\hline 9353 & Slit homologue 2 (Drosophila) & SLIT2 & -3.48 & 4.32E-08 & $3.81 \mathrm{E}-07$ & Cell migration and axonal navigation \\
\hline 4094 & $\begin{array}{l}\text { v-maf musculoaponeurotic fibrosarcoma } \\
\text { oncogene homologue (avian) }\end{array}$ & MAF & -3.46 & $1.41 \mathrm{E}-06$ & $6.35 \mathrm{E}-06$ & $\begin{array}{l}\text { Transcriptional activator or repressor, } \\
\text { oncogene or tumor suppressor depending } \\
\text { on context }\end{array}$ \\
\hline 123624 & ATP/GTP binding protein-like 1 & AGBL1 & -3.37 & $7.95 \mathrm{E}-06$ & $2.66 \mathrm{E}-05$ & Tubulin processing \\
\hline 4629 & Myosin, heavy chain 11 , smooth muscle & MYH11 & -3.31 & 2.09E-06 & $8.78 \mathrm{E}-06$ & Contractile protein \\
\hline
\end{tabular}

COPD, chronic obstructive pulmonary disease; pFDR, positive false discovery rate; TGF $\beta$, transforming growth factor $\beta$.

$(p=0.013)$ (see table E6 in online supplement). There was no overall difference in pack years between the groups $(p=0.106)$. Subjects with GOLD stage 4 tended to have more smoke exposure than smokers without airflow limitation ( $p=0.068$; see table E7 in online supplement). The overall difference in scores on the St George Respiratory Questionnaire and forced expiratory volume in $1 \mathrm{~s}$ percentage predicted were significant $(p<0.0001)$ as expected (see table E8 in online supplement).

\section{MicroRNAs are differentially expressed between COPD and control lung tissues}

Seventy miRNAs were differentially expressed between COPD tissue $(\mathrm{N}=19)$ and tissue from smokers without airflow limitation $(\mathrm{N}=8)$, as shown in figure 1 . Thirteen miRNAs were downregulated in COPD tissue and 57 were upregulated. $m i R-223$ and $m i R-1274 a$ were increased in expression by nearly threefold in COPD samples compared with smokers without airflow limitation (table 2). miR-923 had an average decrease in expression of fivefold in COPD tissue compared with tissue from smokers without airflow limitation (table 3).

\section{QT-PCR validation of differentially expressed microRNAs between COPD and control lung tissues}

We validated miRNAs (miR-15b, miR-223, miR-1274a and $m i R-424)$ by qRT-PCR, as shown in figure 2 . miR-223 and miR$1274 a$ were chosen for further validation based on dramatic increases in expression in COPD samples. $m i R-15 b$ and $m i R-424$ were chosen for validation based on target prediction results and the potential role of these miRNAs in enriched pathways including TGF- $\beta$. The expression of $m i R-223, m i R-1274 a, m i R-15 b$ and miR-424 was verified by quantitative PCR between all COPD samples $(n=26)$ and all tissue samples from smokers without airflow limitation $(n=9)$ and found to be of statistical significance (figure 2).
Figure 4 Quantitative reverse transcription polymerase chain reaction (qRT-PCR) validation of differentially expressed mRNAs. qRT-PCR was performed on the same RNA samples by mRNA TaqMan assay for (A) interleukin 6 (IL-6); (B) telomerase associated protein 1 (TEP1); (C) catalase (CAT) and (D) mothers against decapentaplegic homologue 7 (Drosophila) (SMAD7). All RT-PCR experiments were performed in three independent experiments conducted in triplicate. Data are presented as $2^{(-\Delta C t)}$ relative to $18 \mathrm{~s}$ RNA. In cases in which $p<0.0001$, values are presented as $\mathrm{p}=0.0001$.
A

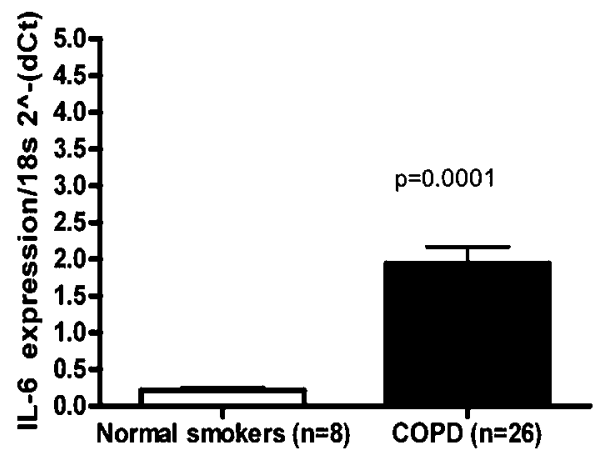

C

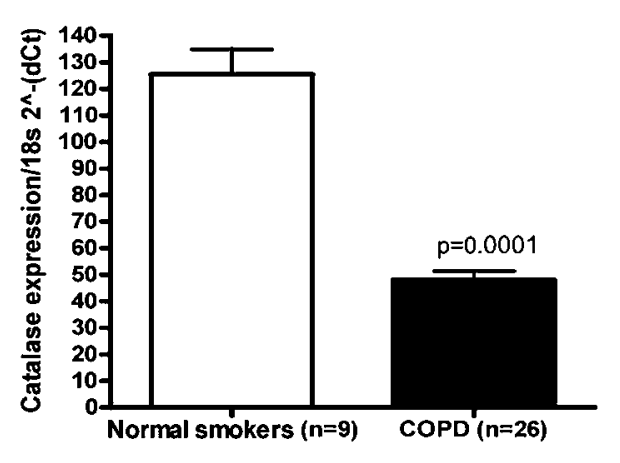

B

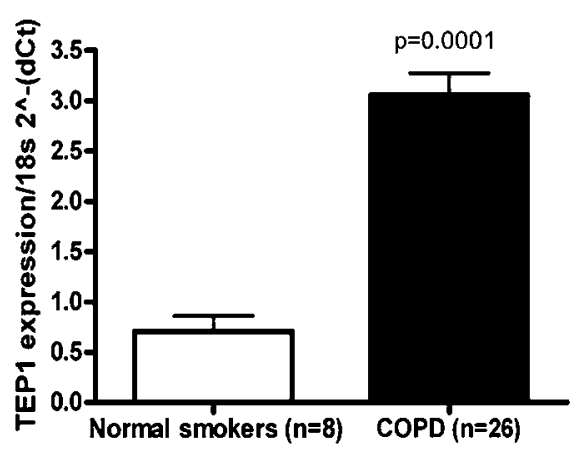

D

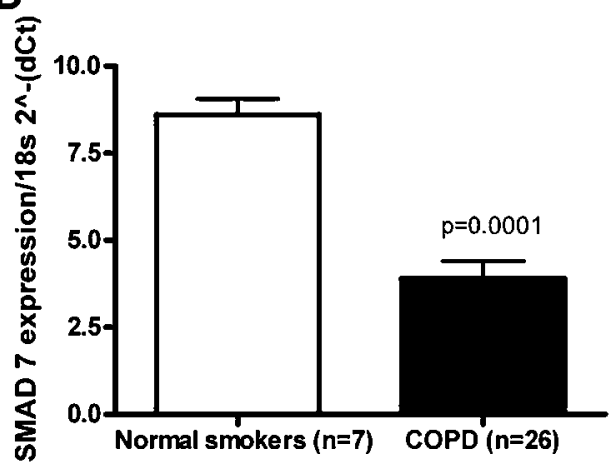


Figure 5 Transforming growth factor $\beta$ (TGF $\beta$ ) pathway in chronic obstructive pulmonary disease. Network representing TGF $\beta$ pathway was manually curated by combining KEGG pathway information and predicted targets of DEmiRNAs. Nodes represent deregulated genes (circles) in the pathway and DEmiRNAs (diamonds) predicted to be associated with the pathway. Node colours (red, upregulated; green, downregulated) represent fold changes of the corresponding genes. Deregulated genes and DEmiRNAs are indicated by bold symbols.

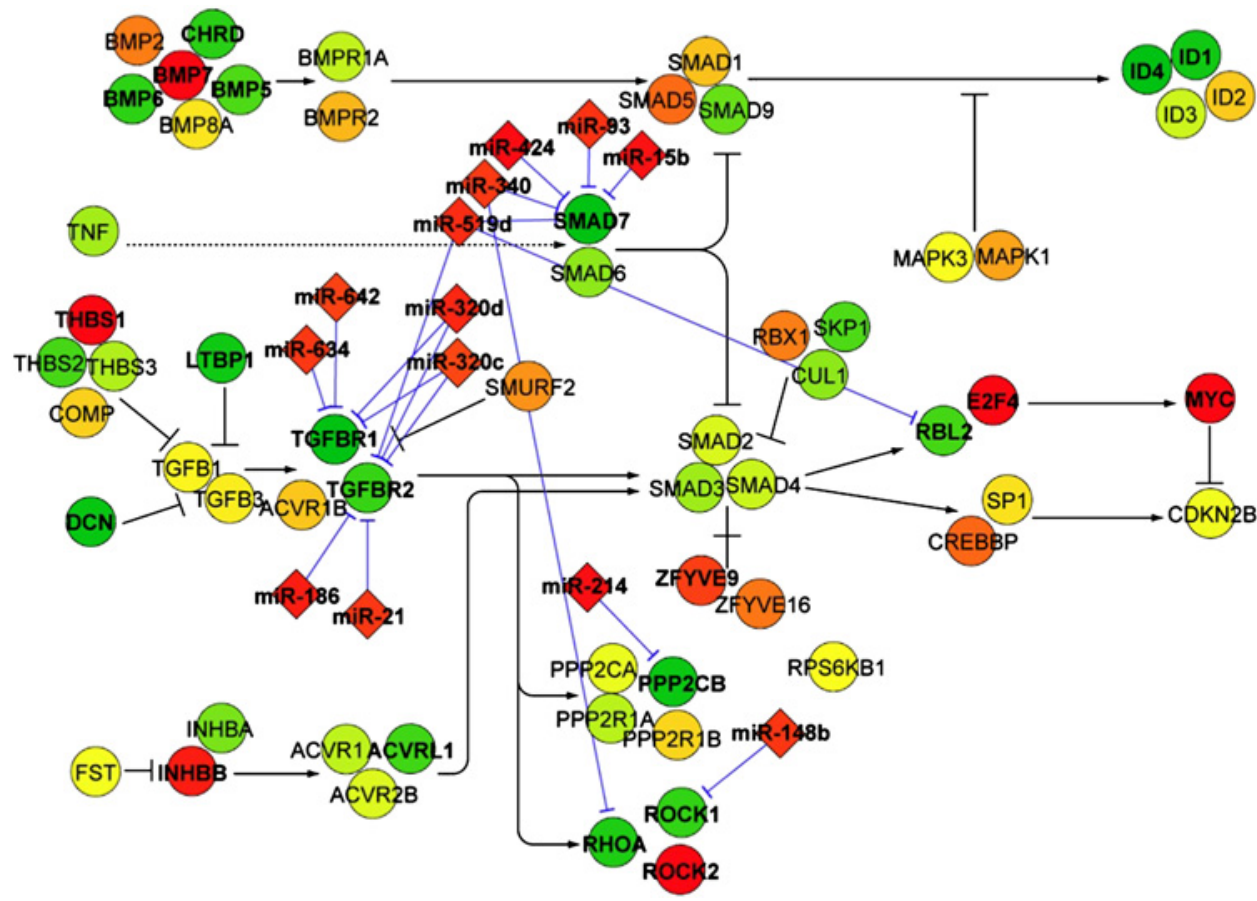

\section{mRNAs are differentially expressed between COPD and control} lung tissues

A comparison of microarray hybridisation results of 23 COPD lung samples and nine samples from smokers without airflow limitation revealed a total of 2667 genes that differed in expression between the two groups (fold change $> \pm 1.5$ and pFDR <0.05; figure 3). Tables 4 and 5 show the 10 genes with the largest fold changes in each direction and their known biological function in expression between COPD tissue and tissue from smokers without airflow limitation.

\section{qRT-PCR validation of differentially expressed genes between COPD and control lung tissues}

The levels of IL-6, TEP1, CAT and SMAD7 were selected to be verified by qRT-PCR (figure 4). SMAD7, which has been investigated in the pathogenesis of COPD, ${ }^{21}$ was markedly decreased in expression based on microarray analysis and validated by qRT-PCR (figure 4). As previously described in the literature, IL-6 22 was increased in COPD samples compared with smokers without airflow limitation, while CAT $^{24}$ was decreased. TEP1, a mammalian protein that is associated with telomerase activity, was significantly increased in expression in our COPD samples compared with controls (figure 4). Matrix metalloproteinase- 9,25 tumour necrosis factor $\boldsymbol{\alpha}$-induced protein 3 (TNFAIP3), ${ }^{26} \mathrm{CSF3}^{27}$ and thrombospondin-1 (THBS1) ${ }^{28}$ were also validated as increased in COPD samples compared with smokers without airflow limitation (data not shown).

\section{TGF $\beta$ and WNT pathways are enriched by miRNA and mRNA expression profiling}

We identified putative miRNA interacting targets using Targetscan, miRanda and PicTar which revealed interacting pairs between differentially expressed miRNAs (DEmiRNAs) and differentially expressed genes (DEGs). Among these pathways, Wnt, TGF $\beta$ signalling and focal adhesion pathways were significantly enriched by DEGs themselves and DEmiRNA-targeted DEGs predicted by three methods (see table E4 in online supplement).

Studies to date suggest a role for TGF $\beta$ in the pathogenesis of $\mathrm{COPD}^{29}$ and there are also current reports linking the Wnt pathway to COPD. ${ }^{30}$ In figure 5 , THBS1, inhibin $\beta$ B (INHBB), Rho-associated coiled-coil containing protein kinase (ROCK) 2, SMAD-specific E3 ubiquitin protein ligase 1 (SMURF1), bone morphogenetic protein 7 (BMP7) and E2F transcription factor 4 (E2F4) were upregulated in COPD (red) while activin A receptor type I (ACVR1), SMAD7, ROCK1, latent TGF $\beta$ binding protein 1 (LTBP1), TGF $\beta$ receptor (TGFBR) 1 and TGFBR2 were downregulated (green). Several differentially expressed genes that are potential targets of differentially expressed miRNAs in the same tissue in the Wnt and focal adhesion pathways are shown in figures E2 and E3 in the online supplement. We chose to focus further attention on the interaction between miR-15b and SMAD7.

\section{miR-15b localises to bronchial epithelium in COPD tissue}

Based on in situ hybridisation for miR-15b in a representative case of a smoker with COPD as depicted in figure 6, miR-15b localised to both the bronchial epithelium and alveolar wall in type II pneumocytes (figure 6B,D). In addition, $m i R-156$ was evident in areas of emphysema as well as fibrosis (figure 6E). Minimal SMAD7 was detectable in these same regions. However, we detected SMAD7 in normal bronchial epithelium and stromal cells (figure 6G,H). Importantly, co-localisation studies using Nuance co-labelling showed that the expression of SMAD7 was decreased in the presence of miR-15b (figure 7). Colocalisation miR-15b and the epithelial-specific AE $1 / 3$ demonstrated an intense yellow signal, thus serving as a positive control (figure 7E,F).

\section{miR-15b targets SMAD7 in bronchial epithelial cells and alters TGF $\beta$ signalling}

SMAD7 is a predicted target of miR-15b (figure 8A). Overexpression of $m i R-15 b$ in Beas $2 B$ bronchial epithelial cells resulted in decreased SMAD7, decorin and SMURF2 protein expression (figure $8 \mathrm{~B}$ ). Knockdown of $m i R-15 b$ resulted in increased SMAD7, decorin and SMURF2 proteins. SMAD7 functions as an inhibitory SMAD in TGF $\beta$ signalling. We therefore sought to determine if miR-15b manipulation and thus SMAD7 expression would alter the cellular response to TGF $\beta$. miR-15b overexpressing Beas $2 \mathrm{~B}$ cells exhibited increased early phosphorylated 

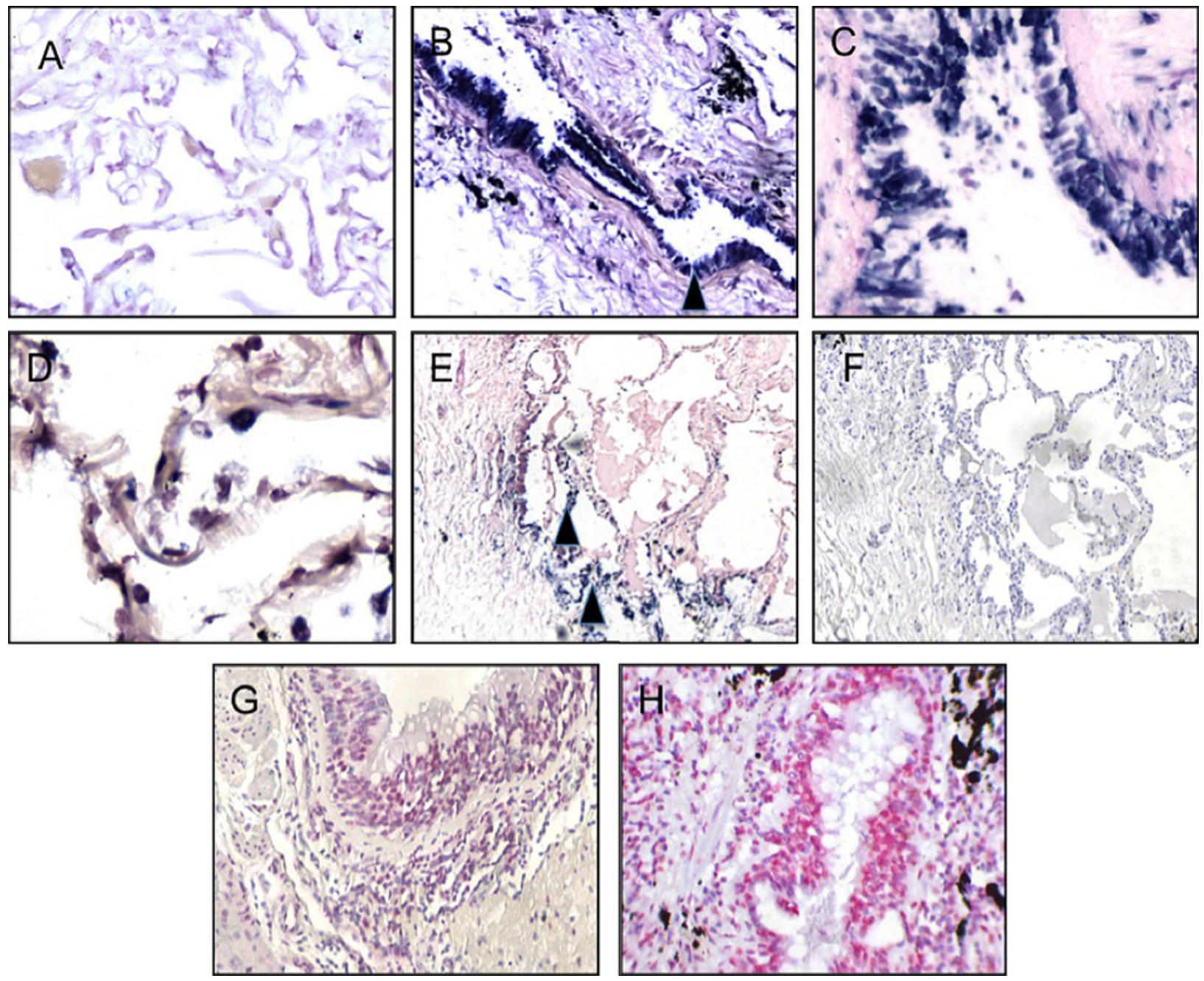

Figure 6 In situ hybridisation for mature miR-15b. Correlation of miR-15b and mothers against decapentaplegic homologue 7 (Drosophila) (SMAD7) expression with lung histopathology. (A) Lack of expression of scrambled miRNA as a control. (B) Normal lung where the miR-15b signal is intense in the epithelial cells of larger bronchi (arrowhead) (each image at $200 \times$ ). (C) Same area at higher magnification $(400 \times)$ where a nuclear and cytoplasmic signal is evident. (D) miR-15b signal in alveoli in a patient with emphysema and increased lung fibrosis $(400 \times)$. (E) miR-15b in epithelial cells at the junction of areas of emphysema and fibrosis (arrowheads) (50×). (F) Same region showing no SMAD7 (50×). (G) SMAD7 in normal regions of bronchial epithelium (red stain) $(100 \times)$. (H) Distribution of SMAD7 protein in a normal larger bronchus in a section of lung $(200 \times)$. The nuclear-based signal involves primarily bronchial epithelial cells and mononuclear cells in the adjacent lymphoid infiltrate.

SMAD3 in response to TGF $\beta$ treatment. (figure $8 \mathrm{C}$ ). miR-15b knockdown had the opposite effect with reduced early phosphorylation of SMAD3 (figure 8C) Lastly, we examined the effects of miR-15b on Beas $2 \mathrm{~B}$ proliferative and migratory capacity, both of which are altered by TGF $\beta$. Cells transfected with miR-15b demonstrated increased migration (figure 8D) and attenuated proliferative capacity (not shown).

\section{DISCUSSION}

We conducted a comprehensive analysis of miRNA and mRNA expression in whole lung samples from subjects with COPD compared with smokers without COPD and identified 70 differentially expressed miRNAs in COPD tissue compared with tissue from smokers without airflow limitation. miR-223 and miR-1274a were the most differentially expressed miRNAs with a near threefold increase in expression in COPD samples. miR$1274 a$ has yet to be well described, and recent studies suggest that it harbours significant homology with the transfer RNA Lysine 5 (tRNA ${ }^{\text {Lys } 5}$ ). ${ }^{31}$ tRNAs are primarily responsible for amino acid transfer. ${ }^{31}$ Two recent studies demonstrated upregulation of miR-223 in murine lungs following exposure to aerosolised lipopolysaccharide and downregulation following exposure to cigarette smoke. ${ }^{79}$

We compared our list of differentially expressed miRNAs with those previously reported in smokers by Schembri et al. ${ }^{11}$ The miRNAs that were differentially expressed in our study as well as the previous report included miR-223, miR-18a, miR-106a, miR-146, $m i R-99 a, m i R-150$ and $m i R-365$. Of these differentially expressed miRNAs, however, miR-18a and miR-365 were the only ones that were increased in expression in both datasets. While the previous study examined airway epithelial cells, we examined whole lung tissue in this study. This may account for the differences in expression patterns. In our study we found increased expression of miR-146a in subjects with COPD compared with smokers without obstruction. The previous study by Sato and colleagues reported reduced expression of $m i R-146 a$ in cultured fibroblasts from COPD subjects. ${ }^{12}$ Again, this was a cell-specific finding as opposed to our whole lung expression analysis. Lastly, Van Pottelberge et al recently identified differences in miRNA expression (including decreased $L e t-7 c$ ) in induced sputum from smokers and individuals with COPD. ${ }^{32}$ The authors determined that predicted target genes for Let-7c were enriched for in sputum from patients with COPD. 
Figure 7 Co-expression of miR-15b and mothers against decapentaplegic homologue 7 (Drosophila) (SMAD7) in the lung. This is a representative section of the lung of a subject with chronic obstructive pulmonary disease and associated increased pulmonary fibrosis. All panels are at $200 \times$. (A) Regular colour image after coexpression of miR-15b (blue) and SMAD7 (brown). The images were analysed by the Nuance system which converted the miR-15b image to fluorescent blue $(B)$ and the SMAD7 image to fluorescent red $(C$, note the stromal dominance). (D) Mixed image where the absence of fluorescent yellow indicates that the cells expressing miR-15b are mutually exclusive from those expressing SMAD7. As a positive control, (E) represents co-expression of miR-15b (blue) and AE $1 / 3$ (brown) in the bronchial epithelium. (F) Co-localisation is evident by the intense yellow signal.
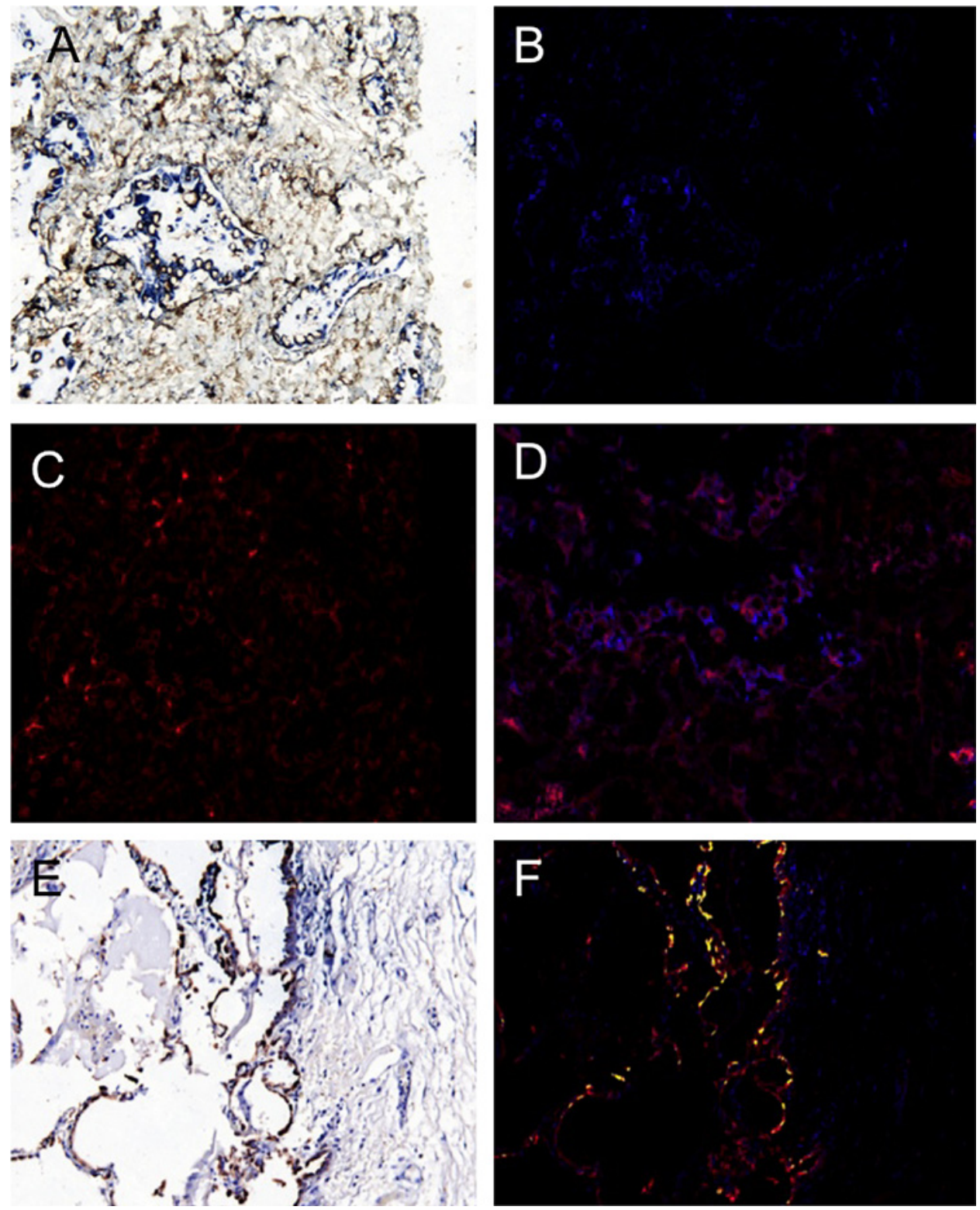

Several genes that are part of the TGF $\beta$ superfamily were differentially expressed in our data. We identified downregulation of BMP5 and BMP6, TGF $\beta$ R 1 and TGF $\beta$ R2 and SMAD7. SMAD7 was of particular interest given that it is downregulated in bronchial biopsies of patients with COPD and serves as an inhibitory SMAD in TGF $\beta$ signalling. ${ }^{33}$ We validated SMAD7 expression in COPD lung tissue by qRT-PCR and by protein in a subset of patients (see figure $\mathrm{E} 4$ in online supplement).

miR-15b, 424 and 107, which were all increased in COPD lung tissue, are members of the miR15/107 family. ${ }^{34}$ Termed the AGCx2 miRNAs because of their common $5^{\prime}$ end (AGCAGC), this group of miRNAs has been implicated in several processes including cell division, stress, angiogenesis and cancer. ${ }^{34}$ Lung tissue from patients with GOLD stage 4 COPD had the highest expression of $m i R-15 b$ compared with subjects with other GOLD stages and normal smokers (see figure E1 in online supplement). We demonstrated that overexpression of $m i R-15 b$ in a bronchial epithelial cell line reduced SMAD7, SMURF2 and downstream decorin protein. Conversely, knockdown of miR-15b resulted in increased SMAD7, decorin and SMURF2 proteins. Functionally, miR-15b manipulation altered early SMAD3 phosphorylation in response to TGF $\beta$ treatment.
Wnt (Wingless and Int-1) signalling has been implicated in normal epithelial and mesenchymal function during lung development and dysregulation observed in lung cancer, pulmonary fibrosis and pulmonary hypertension. ${ }^{35}$ Dysregulation of several Wnt pathway-related genes in COPD has recently been reported in COPD. ${ }^{30}$ Expression of Wnt receptors frizzled homologue (FZD) 5 and FZD 7 were downregulated by 1.76-fold and 1.57-fold, respectively, in our data. With the integration of mRNA and miRNA profiling, we identified several miRNAs that may target the main hubs of this network (see figure E2 in online supplement).

In this study we have presented both mRNA and miRNAs in COPD lung tissue compared with smokers without obstruction. We recognise the limitations of this study, including the lack of phenotypic information of importance such as body composition, frequency of exacerbations, hypoxaemia, perception of dyspnoea or systemic involvement of disease. Our samples were defined by GOLD stages based on spirometric values. There is an inherent limitation in defining patients with COPD by these criteria alone since different phenotypes of disease exist in COPD. We were able to evaluate the available clinical information on these subjects, but factors such as oxygen use, inhaled 
A

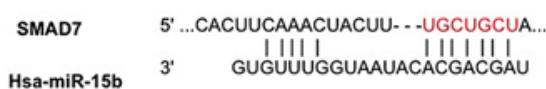

C PSMAD 3

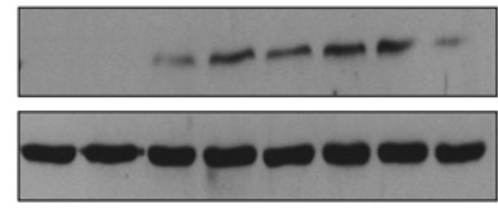

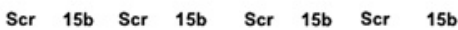

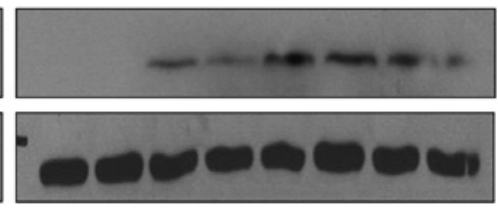

Ser anti-15b Ser anti-15b Ser anti-15b Scr anti-15b
B

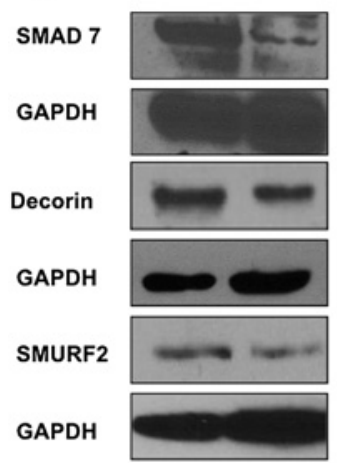

SMAD 7

\section{Decorin}

GAPDH

SMURF2

GAPDH
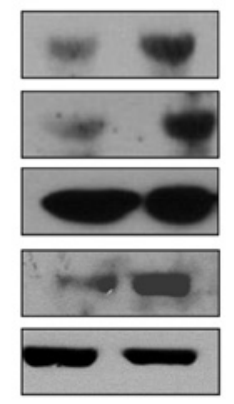

Scr Anti-15b

D

Time 0

Scr Pre-15b

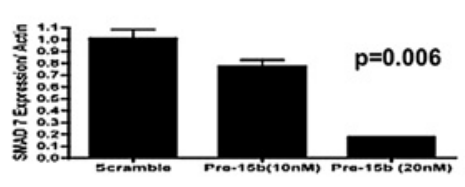

$15 \mathrm{~m} \quad 30 \mathrm{~m}$

$010 \mathrm{~m} \quad 15 \mathrm{~m}$

$30 \mathrm{~m}$

Time $24 \mathrm{~h}$

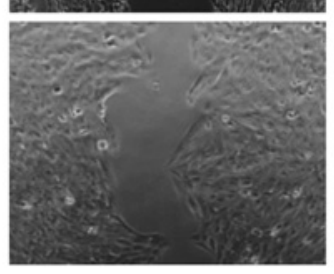

Scrambled

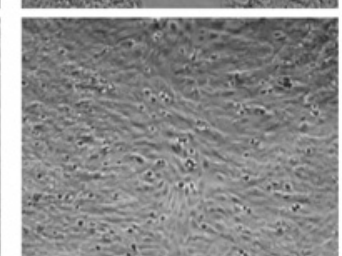

Pre-15b

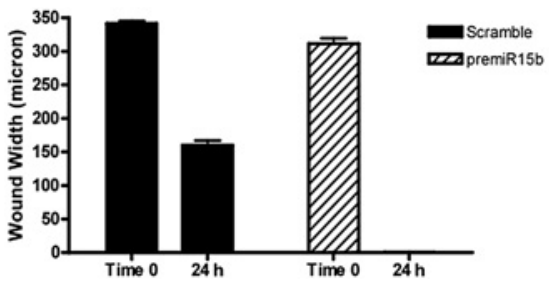

Figure 8 miR-15B targeting mothers against decapentaplegic homologue 7 (Drosophila) (SMAD7) in bronchial epithelial cells. (A) Complementarity of $5^{\prime}$ sequence of miR15- $b$ and 3' UTR of SMAD7. In Beas2B cells, miR-15b overexpression reduced SMAD7 mRNA and protein. miR-15b overexpression reduced decorin and SMURF 2 proteins. miR-15b knockdown led to increased SMAD7, decorin and SMURF2 proteins. (B) Beas2B cells with miR-15b overexpression exhibited increased phosphorylated SMAD3 at 10 and 15 min in response to treatment with transforming growth factor $\beta$ (TGF $\beta$ ) (5 ng/ $\mathrm{ml}$ ). Beas2B cells with miR-15b knockdown exhibited decreased phosphorylated SMAD3 at 10 and 15 min in response to treatment with TGF $\beta$ (5 ng/ $\mathrm{ml}$ ). (C) miR-15b overexpression led to increased migratory capacity in Beas2B cells at $24 \mathrm{~h}$. (D) Quantitative reverse transcription polymerase chain reaction is representative of experiments conducted in triplicate. Statistical significance was determined by ANOVA.

steroid use and time since the last cigarette use were not available in the dataset. In addition, we recognise the lack of reproducibility between high throughput studies of the transcriptome and proteome over the past decade. ${ }^{36-38}$ These differences may be due to tissue heterogeneity and differences in platforms. However, overall, a few common gene ontology terms are consistently deregulated including cellular organisation and biogenesis, response to stress, organ development, cell adhesion and cellular metabolic process. ${ }^{36-38}$

We propose several miRNAs-including members of the miR 15/107 family-that deserve further investigation in the regulation of TGF $\beta$ signalling in COPD. Expressed miRNAs and mRNAs viewed as networks should generate hypotheses about the key pathologies of inflammation and tissue destruction in this and other diseases of the lung.

Acknowledgements We thank the Lung Tissue Research Consortium (LTRC) for collecting and providing subject specimens.

Funding This work was supported by NIH grant R03 HL095425 (SNS) and by the Flight Attendant Medical Research Institute (FAMRI) (MEE), Pulmonary Systems Biology Initiative of the Battelle Memorial Institute (KW, SZ, RG) as well as support from the University of Luxembourg and the Luxembourg Centre for Systems Biomedicine (DG, KW, JHC, RG).

Competing interests None.
Ethics approval This study was approved by IRB Ohio State University.

Contributors ME, SPN, MC, KW, RG, JC, PD and DG were responsible for preparation of the manuscript; $\mathrm{MC}, \mathrm{RO}$ and $\mathrm{KB}$ conducted in vitro experiments; $\mathrm{GN}$ conducted all immunohistochemistry and in situ studies; KW, JC and LY conducted all network and statistical array analysis.

Provenance and peer review Not commissioned; externally peer reviewed.

Data sharing statement All data generated will be uploaded to the appropriate online genomic data banks.

\section{REFERENCES}

1. Fabbri LM, Hurd SS; GOLD Scientific Committee. Global strategy for the diagnosis, management and prevention of COPD: 2003. Eur Respir J 2003;22:1-2.

2. Barnes PJ, Shapiro SD, Pauwels RA. Chronic obstructive pulmonary disease: molecular and cellular mechanisms. Eur Respir J 2003;22:672-88.

3. Ambros V. The functions of animal microRNAs. Nature 2004;431:350-5

4. Lim LP, Lau NC, Garrett-Engele P, et al. Microarray analysis shows that some microRNAs downregulate large numbers of target mRNAs. Nature 2005; 433:769-73.

5. Nana-Sinkam SP, Hunter MG, Nuovo GJ, et al. Integrating the MicroRNome into the study of lung disease. Am J Respir Crit Care Med 2009;179:4-10.

6. Nana-Sinkam SP, Karsies T, Riscili B, et al. Lung MicroRNA: from development to disease. Expert Rev Respir Med 2009:3:373-85.

7. Moschos SA, Williams AE, Perry MM, et al. Expression profiling in vivo demonstrates rapid changes in lung microRNA levels following lipopolysaccharideinduced inflammation but not in the anti-inflammatory action of glucocorticoids. BMC Genomics 2007:8:240. 
8. Zhai Y, Zhong Z, Chen CY, et al. Coordinated changes in mRNA turnover, translation, and RNA processing bodies in bronchial epithelial cells following inflammatory stimulation. Mol Cell Biol 2008;28:7414-26.

9. Izzotti A, Calin GA, Arrigo $P$, et al. Downregulation of microRNA expression in the lungs of rats exposed to cigarette smoke. FASEB J 2009;23:806-12.

10. Izzotti A, Calin GA, Steele VE, et al. Relationships of microRNA expression in mouse lung with age and exposure to cigarette smoke and light. FASEB J 2009:23:3243-50.

11. Schembri F, Sridhar S, Perdomo C, et al. MicroRNAs as modulators of smokinginduced gene expression changes in human airway epithelium. Proc Natl Acad Sci U $S$ A 2009;106:2319-24.

12. Sato T, Liu X, Nelson A, et al. Reduced MiR-146a increases prostaglandin E2 in chronic obstructive pulmonary disease fibroblasts. Am J Respir Crit Care Med 2010;182:1020-9.

13. Bolstad BM, Irizarry RA, Astrand M, et al. A comparison of normalization methods for high density oligonucleotide array data based on variance and bias. Bioinformatics 2003;19:185-93.

14. Smyth GK. Linear models and empirical bayes methods for assessing differentia expression in microarray experiments. Stat Appl Genet Mol Biol 2004:3:Article3.

15. Storey JD, Tibshirani R. Statistical significance for genomewide studies. Proc Nat/ Acad Sci U S A 2003:100:9440-5.

16. McClintick JN, Edenberg HJ. Effects of filtering by Present call on analysis of microarray experiments. BMC Bioinformatics 2006; 7:49.

17. Kanehisa M, Goto S. KEGG: kyoto encyclopedia of genes and genomes. Nucleic Acids Res 2000;28:27-30.

18. Huang da W, Sherman BT, Lempicki RA. Systematic and integrative analysis of large gene lists using DAVID bioinformatics resources. Nat Protoc 2009:4:44-57.

19. Shannon P, Markiel A, Ozier 0, et al. Cytoscape: a software environment for integrated models of biomolecular interaction networks. Genome Res 2003:13:2498-504.

20. Nuovo GJ, Elton TS, Nana-Sinkam P, et al. A methodology for the combined in situ analyses of the precursor and mature forms of microRNAs and correlation with their putative targets. Nat Protoc 2009:4:107-15.

21. Zandvoort A, Postma DS, Jonker MR, et al. Altered expression of the Smad signalling pathway: implications for COPD pathogenesis. Eur Respir $J$ 2006:28:533-41.

22. He J0, Foreman MG, Shumansky K, et al. Associations of IL6 polymorphisms with lung function decline and COPD. Thorax 2009:64:698-704.

23. Kuhn C 3rd, Homer RJ, Zhu Z, et al. Airway hyperresponsiveness and airway obstruction in transgenic mice. Morphologic correlates in mice overexpressing interleukin (IL)-11 and IL-6 in the lung. Am J Respir Cell Mol Biol 2000:22:289-95.
24. Tomaki M, Sugiura $H$, Koarai $A$, et al. Decreased expression of antioxidant enzymes and increased expression of chemokines in COPD lung. Pulm Pharmacol Ther 2007;20:596-605.

25. Churg A, Wang R, Wang X, et al. Effect of an MMP-9/MMP-12 inhibitor on smokeinduced emphysema and airway remodelling in guinea pigs. Thorax 2007:62:706-13

26. Churg A, Dai J, Tai H, et al. Tumor necrosis factor-alpha is central to acute cigarette smoke-induced inflammation and connective tissue breakdown. Am J Respir Crit Care Med 2002;166:849-54.

27. He JO Shumansky K, Connett JE et al. Association of genetic variations in the CSF2 and CSF3 genes with lung function in smoking-induced COPD. Eur Respir J 2008;32:25-34.

28. Wang IM, Stepaniants S, Boie Y, et al. Gene expression profiling in patients with chronic obstructive pulmonary disease and lung cancer. Am J Respir Crit Care Med 2008;177:402-11.

29. Barnes PJ. The cytokine network in chronic obstructive pulmonary disease. Am Respir Cell Mol Biol 2009;41:631-8.

30. Kneidinger $\mathbf{N}$, Yildirim AO, Callegari J, et al. Activation of the WNT/beta-catenin pathway attenuates experimental emphysema. Am J Respir Crit Care Med 2011;183:723-33.

31. Schopman NC, Heynen S, Haasnoot J, et al. A miRNA-tRNA mix-up: tRNA origin of proposed miRNA. RNA Biol 2010;7:573-6.

32. Pottelberge GR, Mestdagh P, Bracke KR, et al. MicroRNA expression in induced sputum of smokers and patients with chronic obstructive pulmonary disease. Am $\mathrm{J}$ Respir Crit Care Med 2011;183:898-906

33. Springer J, Scholz FR, Peiser C, et al. SMAD-signaling in chronic obstructive pulmonary disease: transcriptional down-regulation of inhibitory SMAD 6 and 7 by cigarette smoke. Biol Chem 2004;385:649-53.

34. Finnerty JR, Wang WX, Hebert SS, et al. The miR-15/107 group of microRNA genes: evolutionary biology, cellular functions, and roles in human diseases. $\mathrm{J} \mathrm{Mol}$ Biol 2010;402:491-509.

35. Konigshoff $\mathbf{M}$, Eickelberg 0 . WNT signaling in lung disease: a failure or a regeneration signal? Am J Respir Cell Mol Biol 2010;42:21-31.

36. Golpon HA, Coldren CD, Zamora MR, et al. Emphysema lung tissue gene expression profiling. Am J Respir Cell Mol Biol 2004:31:595-600.

37. Ning W, Li CJ, Kaminski N, et al. Comprehensive gene expression profiles reveal pathways related to the pathogenesis of chronic obstructive pulmonary disease. Proc Natl Acad Sci U S A 2004;101:14895-900.

38. Spira A, Beane J, Pinto-Plata $V$, et al. Gene expression profiling of human lung tissue from smokers with severe emphysema. Am J Respir Cell Mol Biol 2004:31:601-10.

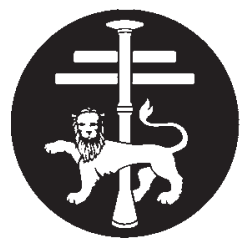

British Thoracic Society

BTS SHORT COURSE

Practical update on the Management of Pulmonary Embolism

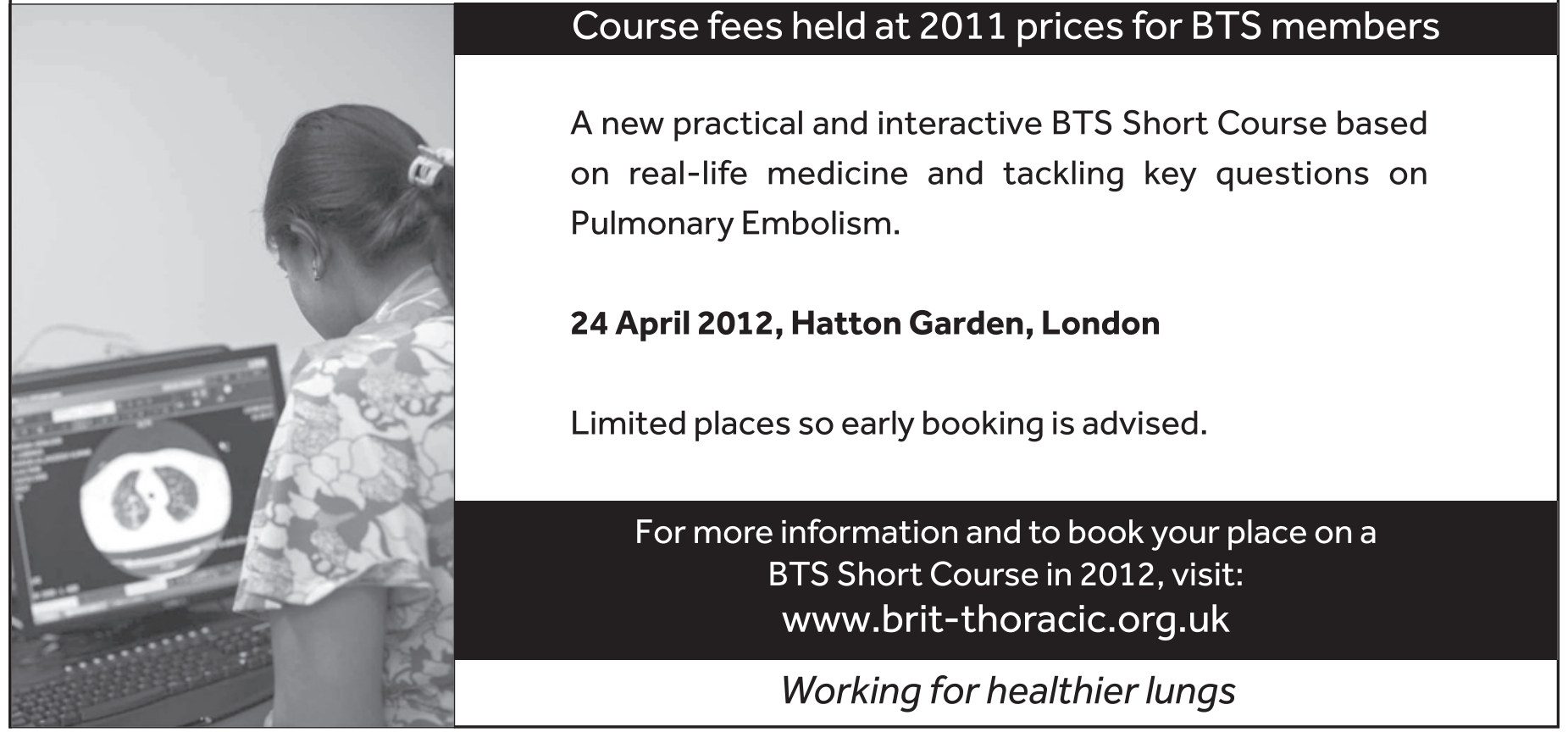

